\title{
Evaluating the Investment in the Malaysian Construction Sector in the Long-run Using the Modified Internal Rate of Return: A Markov Chain Approach*
}

\author{
Wajeeh Mustafa SARSOUR ${ }^{1}$, Shamsul Rijal Muhammad SABRI ${ }^{2}$
}

Received: June 03, 2020 Revised: July 05, 2020 Accepted: July 12, 2020

\begin{abstract}
In capital budgeting practices, investment project evaluations based on the net present value (NPV) and the internal rate of return (IRR) represent the traditional evaluation techniques. Compared with the traditional methods, the modified internal rate of return (MIRR) gives the opportunity to evaluate an investment in certain projet, while taking the changes in cash flows over time and issuing shares such as dividing shares, bonuses, and dividend for each end of the investment year into account. Therefore, this study aims to evaluate an investment in the Malaysian construction sector utilizing financial data for 39 public listed companies operating in the Malaysian construction sector over the period from Jan 1, 2007, to December 30, 2018, based on the MIRR method. Stochastic was studied in this study to estimate the estimated probability by applying the Markov chain model to the MIRR method where the transition matrix has two possible movements of either Good (G) or Bad (B). it is found that the long-run probability of getting a good investment is higher than the probability of getting a bad investment in the long-run, where were the probabilities of good and bad are $0.5119,0.4881$, respectively. Hence, investment in the Malaysian construction sector is recommended.
\end{abstract}

Keywords: NPV, MIRR, Investment Evaluation, Malaysian Construction Sector, Markov Chain

JEL Classification Code: C73, D92, E17, E22

\section{Introduction and Background}

Stock prices play a vital role in helping investors' investment decisions in terms of predicting the stock market behavior in both the short-term and long-term. These stock

\footnotetext{
*Acknowledgements:

The authors would like to express their sincere thanks to the editor and anonymous reviews for their time and valuable suggestions. This research was supported in part by the School of Mathematical Sciences at Universiti Sains Malaysia.

${ }^{1}$ First Author and Corresponding Author. School of Mathematical Sciences, Universiti Sains Malaysia, Pinang, Malaysia [Postal Address: 11800, Universiti Sains Malaysia, Gelogur, Pulau Pinang, Malaysia] E-mail: wajeeh.sa88@gmail.com

${ }^{2}$ Lecturer, School of Mathematical Sciences, Universiti Sains Malaysia, Pinang, Malaysia. E-mail: rijal@usm.my

(C) Copyright: The Author(s)

This is an Open Access article distributed under the terms of the Creative Commons Attribution Non-Commercial License (http://Creativecommons.org/licenses/by-nc/4.0/) which permits unrestricted noncommercial use, distribution, and reproduction in any medium, provided the original work is properly cited.
}

prices generally measure the changes in the stock market and represent the trading securities portfolio on a certain market. Therefore, investment performance evaluations have attracted both investors and researchers, where there are many studies that interested in investment (Erum et al., 2016; Le et al., 2019; Dzung et al., 2017). Accordingly, different investment evaluation methods have been applied such as NPV, IRR, and MIRR techniques in capital budgeting based on discounted cash flow (DCF) to detect the feasibility of an investment project (Graham \& Harvey, 2001; Brounen et al., 2004; Bennouna et al., 2010; Brealey et al., 2011; Brigham \& Ehrhardt, 2014; Kengatharan, 2016).

Evidence from academia suggests that the NPV technique is the foremost measure of return on investment because it maximizes equity's market value (Bennouna et al., 2010; Brealey et al., 2011; Kengatharan, 2016). Furthermore, most evaluation methods were performed based on the DCF from the NPV rule where, for example, the root of $\operatorname{NPV}(\mathrm{R})=0$ is equivalent to the IRR (Harvey, 1995). Meanwhile, the IRR technique is mostly favored over the NPV technique as an 
investment performance evaluation instrument (Brounen et al., 2004; Brigham \& Ehrhardt, 2014).

However, evaluations of investment in a certain project using the NPV and IRR may lead to inconsistent results especially when evaluating an investment in two disjoint projects and when cash flows changed over time (i.e., nonconventional cash-flow) (Harvey, 1995; Kulakov \& Kastro, 2017). One main problem of investment evaluation based on the IRR method is that it assumes the reinvestment of the gained positive cash flows at the same rate at which they were created. Moreover, the IRR may have a non-unique solution. These issues have attracted various researchers to develop alternative investment evaluation methods to overcome this problem such as the MIRR method, which has become most frequently used in capital budgeting practices (Solomon, 1956; Lin, 1976; Athanasopoulos, 1978; Balyeat et al., 2013; Ivanović et al., 2015; Kulakov \& Kastro, 2017; Kastro \& Kulakov, 2017; Sabri \& Sarsour, 2019).

The MIRR assumes that the returns obtained from the positive cash flows of an investment project will be reinvested at the external rate of return, which is formally equal to the equity's cost of capital. Some financial analysts assert on implementing the MIRR method for both conventional and non-conventional investment projects (Bernhard, 1979; McDaniel et al., 1988; Kelleher \& MacCormack, 2004; Kierulff, 2008; Balyeat et al., 2013; Ivanović et al., 2015; Kengatharan, 2016), although the MIRR formula is, in fact, simply an additional exhibition of the NPV (Kulakova \& Kulakov, 2014). On the other hand, Kulakov and Kastro (2017) concluded that the IRR method was appropriate in evaluating investment with conventional rather than nonconventional projects. They also showed that the results obtained from the MIRR method may reveal inconsistent results with the NPV method when the cash time flows changed over. Recent evidence by Sabri and Sarsour (2019) has shown that the MIRR can be calculated considering a fixed amount of money at every beginning year of investment besides profits gained from the preceding year to buy shares that will be re-invested. They considered issuing shares such as dividing shares and bonuses as well since they have a clear influence on the value of shares to be invested.

The current study aims to evaluate the investment in the Malaysian construction sector utilizing financial data for 39 public listed companies operating in the Malaysian construction sector over the period from Jan 1, 2007, to December 30, 2018, using the MIRR method proposed by Sabri and Sarsour (2019). Markov chain model is implemented to the MIRR method where the transition matrix has two possible movements of either Good $(\mathrm{G})$ or Bad (B). The study concluded that investment in the Malaysian construction sector is recommended since the long-run probability of getting a good investment is higher than the probability of getting a bad investment in the long-run.

\section{Methodology}

\subsection{Markov Chain Model}

One of the most important fundamental part of stochastic process is the Markov chains models, which have been proposed in ealy 1900s by the Russian mathematician; Andrey Markov. They are applied widely in several fields of science. A Markov chain is defined as a stochastic process that fullfils the Markov property meaning that forecasting the stochastic process in terms of expressing the future independent of the past are independent when the present is known. In other words, if a researcher knows the presents state, then can predict the future state without referring to its past state. Therefore, a large number of parameters is reduced when investigating such a process (Sericola, 2013).

Asuume a sequence $\left\{X_{t}, t=1,2, \ldots\right\}$ satisfies the Markov property. Defining this sequence as a Markov chain process, which is expressed as:

$$
\begin{aligned}
& P\left\{X_{t}=j \mid X_{0}=i_{0}, X_{1}=i_{1}, \ldots, X_{t-1}=i\right\} \\
& =P\left\{X_{t}=j \mid X_{t-1}=i\right\}
\end{aligned}
$$

\subsection{Transition Matrix and Transition Probability Matrix}

Let $f_{i j}(t)$ be the number of observed parameters in state $i$ at the $(t-1)^{s t}$ year and observed in state $j$ at the $t^{\text {th }}$ year. Let $L_{a}$ be the transition count matrices of $a$ for the combined years. Then, the transition count matrices are derived using the formula $L_{a}=\left[f_{i j}\right]$, where $f_{i j}=\sum_{t=1}^{T} f_{i j}(t)$, and the $f_{i}(t-1)=\sum_{t=1}^{r} f_{i k}(t), k=1,2, \ldots, r$, where $r$ is the number of states.

If $p_{i j}(t)$ are independent of time $t$ (i.e., $\left.p_{i j}(t)=p_{i j}\right)$, then the Markov process is called stationary transition probabilities. The maximum likelihood method is used to estimate multinomial trials with probabilities $p_{i j}(i, j=1,2, \ldots, r)$ is written as:

$$
\hat{p}_{i j}=\frac{\sum_{t=1}^{T} f_{i j}(t)}{\sum_{k=1}^{r} \sum_{t=1}^{T} f_{i k}(t)}=\frac{\sum_{t=1}^{T} f_{i j}(t)}{\sum_{t=1}^{T} f_{i}(t-1)}
$$

Once the parameters estimated, we can express the transition probability matrix as follow:

$$
P=\left[\hat{p}_{i j}\right] \text { where } P=\left[\hat{p}_{i j}\right] \sum_{k=1}^{r} \hat{p}_{i j}=1
$$


Furthermore,three types of the stochastic matrices based on the sum of the row, column or both can be described as follow:

(1) If each column summing to 1 , the matrix called a left stochastic matrix.

(2) If each row summing to 1 , the matrix called a right stochastic matrix.

(3) If each column summing to 1 and each row summing to 1 , the matrix called a doubly stochastic matrix.

\subsection{Limiting Distributions "Stationary Distribution of a Markov Chain"}

When multiplying the transition probability matrix, $P$, by itself $\mathrm{n}$ times, the resulting matrix is called the $\mathrm{n}$-step transition probability matrix. Accordingly, its entries $p_{i j}^{n}$ is the conditional probability that the company will stay in state $j$ after $n$ transitions, given that it is currently in state $i$.

$$
p_{i j}^{n}=\operatorname{Pr}\left\{X_{t+n}=j \mid X_{t}=i\right\}
$$

When the class of Markov chain is an aperiodic, irreducible, and finite-state, we can define the long-run behavior of a Markov model, which is known as the limiting distribution, as:

$$
\lim _{n \rightarrow \infty} \operatorname{Pr}\left\{X_{n}=j \mid X_{0}=i\right\}=\omega_{j}, j=1,2, \ldots, r
$$

Specifically, $\omega$ in Equation 5 is a probability measure of distribution stationarity of the chain that has an ergodic property (Sarsour and Sabri, 2020).

\subsection{Expected Number of Visits}

The expected number of visits $\vartheta_{i j}$ made by the chain, which starts from state $i$ to state $j$ is defined as follows:

$$
\vartheta_{i j}(m)=E\left\{N_{i j}(m)\right\}=\sum_{l=1}^{m} P_{i j}^{(l)}
$$

where, $N_{i j}(m)$ is the number of visits from state $i$ to state $j$ in the $m$-steps.

In the long-run, the expected number of visits to state $j$ starting from state $i$ is defined as:

$$
\vartheta_{i j}(m)=\lim _{m \rightarrow \infty} E\left\{N_{i j}(m)\right\}
$$

\subsection{Expected Return Time}

Consider $P^{n}$ is a finite irreducible Markov chain having a limiting distribution denoted by $\omega$, as mentioned earlier. The reciprocal of the limiting distribution exhibits the mean return time to state $j$ it was firstly in at time 0 ,

$$
\tau_{j}=\frac{1}{\omega_{j}}
$$

Where $\tau_{j}, j=1,2, \ldots, r$ is expected return time to state $j$ (Bhusal, 2018).

\subsection{Investment Strategy}

The MIRR investment measure proposed by Sabri and Sarsour (2019) is used to evaluate the long-term investment in the Malaysian construction sector. This strategy relies on investing in a fixed amount of money at every beginning of an investment year besides profits that have been obtained from the previous year to buy shares to be re-invested. Moreover, this proposed strategy considers issuing shares such as dividing shares and bonuses, because they have a clear impact on the value of shares to be invested.

Microsoft Excel is used to calculate MIRR by equalizing the net profit value (NPV) by zero using the following equation:

$$
\begin{gathered}
N P V=F(T)(1+M I R R)^{-\frac{u_{T+1,1}-u_{1,1}}{365}} \\
-\sum_{t=1}^{T+1} C_{t}^{*}(1+M I R R)^{-\frac{u_{t, 1}-u_{1,1}}{365}} \\
=\left[S_{T}^{(2)} P_{u_{T+1,2}}+B_{T}+D I V_{T}\right](1+M I R R)^{-\frac{u_{T+1,1}-u_{1,1}}{365}} \\
-C \sum_{t=1}^{T+1} f_{i j}(t) a_{t}(1+M I R R)^{-\frac{u_{t, 1}-u_{1,1}}{365}}
\end{gathered}
$$

where;

$F(T)$ the terminal value of the invested fund at the end of $\mathrm{T}$ years.

$C_{t}^{*}$ money outflows to the series of yearly contributions.

$D I V_{T}$ the total of dividends.

$B_{T}$ the balance.

$S_{T}^{(2)}$ the accumulated share unit.

$P_{u_{T+1,2}}$ share price sold at a time $u_{T+1,2}$.

\subsection{Define MIRR}

The MIRR has two possible transitions of either good or bad states. These possible movements formulate our two states in the transition probability matrix of the Markov chain model. The chain is defined as a bad1 (B) if the MIRR of year is less than zero while if it is higher than or equal to zero it is defined as a good $2(\mathrm{G})$. The pattern of the movement of 
MIRR bad state $1(\mathrm{~B})$ to good state $2(\mathrm{G})$ is labeled by $12(\mathrm{BG})$ and so on.

Consider $Z_{t}$ is a discrete random variable, which takes two different values and is defined based on the constant number (cost of capital) as follows:

State 1 for negative MIRR, state 2 for positive MIRR or equal zero over the long-term, are identified as follows:

$$
Z_{t}=\left\{\begin{array}{l}
1 M I R R<C \\
2 M I R R \geq C
\end{array}\right.
$$

As a result, the random variable $Z_{t}$ has a two-state Markov chain model (e.g., 1(B), and $2(\mathrm{G})$ ). The number of transitions from state $i$ at time $t$ to state $j$ at time $t+1$ is denoted by $n_{i j}$. Therefore, the transition matrix for a twostate Markov model is given by:

$$
T^{*}=\left[\begin{array}{ll}
f_{11} & f_{12} \\
f_{21} & f_{22}
\end{array}\right]
$$

Now, the transition probability matrix is obtained based on Equation 3, which is given by:

$$
p=\left[\begin{array}{ll}
p_{11} & p_{12} \\
p_{21} & p_{22}
\end{array}\right]
$$

\section{Data Source}

This paper utilizes data of Malaysian stock prices for 39 companies operating in the construction sector. Specifically, stock prices are obtained from the Wall Street Journal (WSJ) besides the financial reports for public listed companies in Bursa Malaysia during the period from Jan 1, 2007, to December 30,2018. The MIRR is being calculated using the stock prices based on the formula listed in the previous section.

\section{Results and Discussion}

\subsection{Derivation of the Two-State Transition Probability Matrix}

From the values of MIRR, it appears that the investment result of the Malaysian construction sector has two possible movements of either good or bad, which are used to determine the transiton probability matrix of the Markov chain model. This probability matrix normally explains the behavior of the Markov chain for which its entries provide information about the transition from one state to the other.

From the transition matrix shown in Table 1, we can estimate the transition probability matrix by using maximum likelihood estimate as shown below

$$
P=\left[\begin{array}{ll}
0.4700 & 0.5300 \\
0.5053 & 0.4947
\end{array}\right]
$$

It seems that the probability of MIRR to the Malaysian construction sector moving from bad to bad state is 0.47 , from a bad state to a good state is 0.53 , from a good state to a bad state is 0.505 , and from good to good state is 0.49 . These probabilities of transitions are illustrated in Figure 1 to simplify reporting the results.

\subsection{Determination of Initial State Vector}

The values of the MIRR for the Malaysian construction sector exhibited two different states: Good (G) and Bad (B) over the study period. Typically, if the MIRR of an investment in the Malaysian construction sector is more than zero (its expected returns), the investment is considered to be good and thus investors are recommended to undertake an investment project in such a sector. However, it is not recommended to invest in this sector if its MIRR is lower than zero. The probability of occurrence of the two different states is derived based on the initial state vector, $\omega(0)=$ $(\omega 1, \omega 2)$; where, $\omega 1$, and $\omega 2$ provide the probability that MIRR of bad and good, respectively.

$$
\begin{aligned}
& \omega 1=129 / 234=0.5512 \\
& \omega 2=105 / 234=0.4488
\end{aligned}
$$

Table 1: The transition matrix of the MIRR measure.

\begin{tabular}{|l|c|c|}
\hline & Bad(1) & Good(2) \\
\hline $\operatorname{Bad}(1)$ & 47 & 53 \\
\hline $\operatorname{Good}(2)$ & 48 & 47 \\
\hline
\end{tabular}

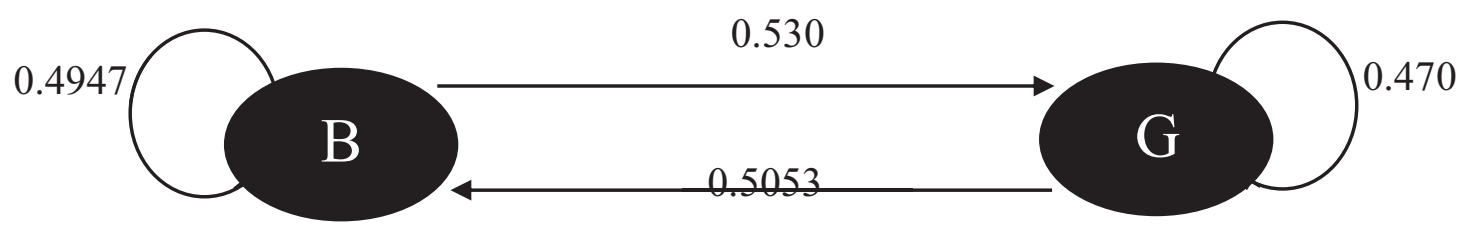

Figure 1: Transition diagram of MIRR for the Malaysian construction sector 
Hence the initial state vector for MIRR is estimated as

$$
\omega(0)=(0.5512,0.4488)
$$

\subsection{Computation of State Probabilities for Forecasting the MIRR}

When multiplying the initial state vector by the transition probability matrix, we can obtain the maximum possibility that the market will be at a specific state.

$$
\begin{aligned}
\omega(1) & =\omega(0) * P=(0.5512,0.4488)\left[\begin{array}{ll}
0.4700 & 0.5300 \\
0.5053 & 0.4947
\end{array}\right] \\
& =(0.4858,0.5142)
\end{aligned}
$$

From these results, it seems that the Malaysian construction based on MIRR investment strategy has a 0.4858 maximum probability of staying in a bad state at the end of the next year period, meaning that the investment may fail, while the MIRR will be at a good state with a maximum probability of 0.5142 at the end of the next year period, meaning that the investment may success.

$$
\omega(2)=\omega(1) * P=(0.4881, \quad 0.5119)
$$

The estimated probability vector in $\omega(2)$ reveals that the MIRR will stay in a Bad state with a probability of 0.4881 , while it will stay in a Good state with a probability of 0.5119 during the next two years period.

\subsection{Decision Making under Long-Run Behavior of MIRR}

Forecasting the long-term behavior of the Malaysian construction sector based on the MIRR might provide a meaningful overlook of its behavior in the near future and thus helping investors improving their investment decisions in such a market. This information can be acquired by calculating the $\mathrm{n}^{\text {th }}$ step transition probability matrix, where it will converge to the limiting distribution for each state as the number of steps increased. The long-term behavior of the MIRR in the Malaysian construction sector is obtained by calculating the higher-order transition matrix in which this matrix tends to be steady or remains unchanged for the onward successive trading years.

$$
\begin{aligned}
& P(2)=\left[\begin{array}{ll}
0.4887 & 0.5113 \\
0.4874 & 0.5126
\end{array}\right] \\
& P(3)=\left[\begin{array}{ll}
0.4880 & 0.5120 \\
0.4881 & 0.5119
\end{array}\right]
\end{aligned}
$$

$$
P(4)=\left[\begin{array}{ll}
0.4881 & 0.5119 \\
0.4881 & 0.5119
\end{array}\right]=P(5)=P(6)=P(7)=\ldots
$$

and so on

The above results reveal that the transition probability matrix got steady after the $4^{\text {th }}$ trading years since 31 Dec 2018. Accordingly, the investment in the stock market of the Malaysian construction sector had a probability of 0.4881 to get Bad in the near future regardless of its initial state while the probability of getting Good in the near future is 0.5119 .

$$
\begin{aligned}
\omega(0) * P(4) & =(0.5512,0.4488)\left[\begin{array}{ll}
0.4881 & 0.5119 \\
0.4881 & 0.5119
\end{array}\right] \\
& =(0.4881,0.5119)
\end{aligned}
$$

Consider that the MIRR of the Malaysian construction sector begins with the initial state vector $\omega(0)$. Multiplying $\omega(0)$ by $P(4)$ will reveal the probability that such a market will get Bad or Good at a certain trading year in a steady state. This finding shows that, at the steady-state, the longterm probability that the investment in the stock market of the Malaysian construction sector will be Bad is 0.4881 and will be Good is 0.5119 .

\subsection{Determination of Expected Numbers of Visits}

The expected numbers of visits to a certain state from others in various steps are calculated to investigate the mean occurrence of time the moving subject visits in a particular state. From the following matrix, $\vartheta_{i j}(2)$, we can determine the number of visits to a specific state in a twoyear investment period.

$$
\vartheta_{i j}(2)=\left[\begin{array}{ll}
0.9587 & 1.0413 \\
0.9927 & 1.0073
\end{array}\right]
$$

It seems that if the MIRR of the Malaysian construction sector begins with a Bad state, the expected number of visits the chain for getting to a Bad state out of two-year investment period is 0.9587 , and to get Good state is 1.0413 . Similarly, the expected number of visits the chain for getting a Good state out of a two-year investment period is 1.0073 if it begins with a Good state.

\subsection{Determination of Expected Return Time}

Investors need to know the duration that the MIRR will stay in a Good or Bad state. In this study, the mean return time to a Good state when the chain starts from a Good state 
is 1.9533 years meaning that the chain should visit the Good state, on average, by 2 years. Similarly, the mean return time to a Bad state starting from Bad state is 2.049 years.

$$
\begin{gathered}
\tau_{B}=\frac{1}{0.4881}=2.0490 \\
\tau_{G}=\frac{1}{0.5119}=1.9533
\end{gathered}
$$

\section{Conclusion}

In capital budgeting practices, cash flows of a certain project may change overtime and issuing shares such as dividing shares may be occurred. Combingning both issues together, the modified MIRR may provide a better fix in evaluating investment in certain projet, which takes into account these issues. Therefore, this study aimd to evaluate the long-term investment in the Malaysian construction sector utilizing financial data for 39 public listed companies operating in the Malaysian construction sector over the period from Jan 1, 2007, to December 30, 2018 using MIRR method. A Markov chain model is adopted to the MIRR method where the transition matrix has two possible movements of either Good $(\mathrm{G})$ or Bad $(\mathrm{B})$.

The implications from this study findings for investors are very important. The study recommended investors to invest in the Malysian construction sector because the longrun probability of getting a good investment is higher than the long-run probability of getting a bad investment.

\section{References}

Athanasopoulos, P. (1978). A Note on the Modified Internal Rate of Return and Investment Criterion. The Engineering Economist, 23(2), 131-133.

Balyeat, R. B., Cagle, J., \& Glasgo, P. (2013). Teaching MIRR to improve comprehension of investment performance evaluation techniques. Journal of Economics and Finance Education, 12(1), 39-50.

Bennouna, K., Meredith, G. G., \& Marchant, T. (2010). Improved capital budgeting decision making: evidence from Canada. Management Decision, 48(2), 225-247.

Bernhard, R. H. (1979). Modified rates of return for investment project evaluation - a comparison and critique. The Engineering Economist, 24(3), 161-168.

Bhusal, M. K. (2018). Application of Markov Chain Model in the Stock Market Trend Analysis of Nepal. International Journal of Scientific and Engineering Research, 8(10), 1733-174.

Brealey, R. A., Myers, S. C., \& Allen, F. (2011). Principles of Corporate Finance (10th ed.). New York, NY: McGraw-Hill.
Brigham, E. F., \& Ehrhardt, M. C. (2014). Financial Management: Theory and Practice (14th ed.). Boston, MA: South Western Cengage Learning.

Brounen, D., de Jong, A., \& Koedijk, K. (2004). Corporate finance in Europe: Confronting theory with practice. Financial Management, 33(4), 71-101.

Dzung, N. T., Tuan, N. A., \& Tinh, D. P. T. (2017). The Role of Investment Attraction in Vietnamese Industrial Parks and Economic Zones in the Process of International Economic Integration. Journal of Asian Finance, Economics, and Business, 4(3), 27-34. http://dx.doi.org/10.13106/jafeb.2017. vol4.no3.27

Erum, N., Hussain, S., \& Yousaf, A. (2016). Foreign direct investment and economic growth in Saarc countries. Journal of Asian Finance, Economics and Business, 3(4), 57-66. https:// doi.org/10.13106/jafeb.2016.vol3.no4.57

Graham, J., \& Harvey, C. (2001). The theory and practice of corporate finance: evidence from the field. Journal of Financial Economics, 60(2-3), 187-243.

Harvey, C. R. (1995). Project Evaluation. Retrieved January 15, 2020 from: https://people.duke.edu/ charvey/Classes/ba350/ project/project.htm

Ivanović, S., Nastić, L., \& Bekić, B. (2015). Possibilities of MIRR method application for evaluation of investments in agriculture: an example of pigs fattening. Economics of Agriculture, 62(2972016-3683), 325-333.

Kastro, A., \& Kulakov, N. (2017). Alternative evaluation methods for non-conventional investment projects. Korporativnye finansy = Journal of Corporate Finance Research, 11(1), 111128.

Kelleher, J., \& MacCormack, J. (2004). Internal Rate of Return: A Cautionary Tale. The McKinsey Quarterly, October, 71-75. McKinsey \& Co.

Kengatharan, L. (2016). Capital Budgeting Theory and Practice: A Review and Agenda for Future Research. Applied Economics and Finance, 3(2), 15-38.

Kierulff, H. (2008). MIRR: A better measure. Business Horizons, $51,321-329$.

Kulakov, N. Y., \& Kastro, A. N. B. (2017). New applications of the IRR Method in the Evaluation of Investment Projects. In IIE Annual Conference Proceedings (pp. 464-469). Institute of Industrial and Systems Engineers (IISE).

Kulakova, A., \& Kulakov, N. (2014). Is the MIRR a Suitable Indicator for Projects with Multiple Outflows?. Proceedings of IIE Annual Conference. Available at: http://www.xcdsystem. com/iie2014/abstract/finalpapers/I92.pdf

Le, N. H., Duy, L. V. Q., \& Ngoc, B. H. (2019). Effects of foreign direct investment and human capital on labour productivity: Evidence from Vietnam. Journal of Asian Finance, Economics and Business, 6(3), 123-130. https://doi.org/10.13106/ jafeb.2019.vol6.no3.123 
Li, W., \& Ng, M. K. (2014). On the limiting probability distribution of a transition probability tensor. Linear and Multilinear Algebra, 62(3), 362-385.

Lin, S. A. (1976). The Modified Internal Rate of Return and Investment Criterion. The Engineering Economist, 21(Summer), 237-247.

McDaniel, W., McCarty, D., \& Jessell, K. (1988). Discounted Cash Flow with Explicit Reinvestment Rates: Tutorial and Extension. The Financial Review, 23(3), 369-385.

Sabri, S. R. M., \& Sarsour, W. M. (2019). Modelling on Stock Investment Valuation for Long-term Strategy. Journal of Investment and Management, 8(3), 60-66.
Sarsour, W. M., \& Sabri, S. R. M. (2020). Forecasting the LongRun Behavior of the Stock Price of Some Selected Companies in the Malaysian Construction Sector: A Markov Chain Approach. International Journal of Mathematical, Engineering and Management Sciences, 5(2), 296-308.

Sericola, B. (2013). Markov chains: theory and applications. Hoboken, NJ: John Wiley \& Sons.

Solomon, E. (1956). The arithmetic of capital budgeting decisions. Journal of Business, 29(2), 124-129. 